\title{
A Study on Mechanical Properties of PMMA/Hydroxyapatite Nanocomposite
}

\author{
Seyed Mojtaba Zebarjad, Seyed Abdolkarim Sajjadi, Tahere Ebrahimi Sdrabadi, \\ Amir Yaghmaei, Behrooz Naderi \\ Department of Materials Science and Metallurgical Engineering, Faculty of Engineering, \\ Ferdowsi University of Mashhad, Mashhad, Iran \\ E-mail: zebarjad@um.ac.ir \\ Received November 7, 2010; revised June 2, 2011; accepted June 15, 2011
}

\begin{abstract}
This study is focused on the role of nano hydroxyapatite particles on the mechanical properties of PMMA/ HA nanocomposites. In order to achieve a proper and homogeneous distribution of HA particles in the polymer matrix, mixer milling process was applied. Wear, compression and three-point bending tests were conducted. It was observed that wear rate decreased by increasing in HA content in both atmosphere and artificial saliva. The results of compression tests showed that the addition of 2.5 percent HA to PMMA promoted ultimate compressive strength, yield strength and modulus while caused to decrease elongation at break. Also it was elucidated that addition of HA more than $2.5 \mathrm{wt} \%$ caused a decrease in both ultimate compressive strength and compression yield strength and an increase in elongation at break. The results of three-point bending tests on the PMMA cements containing 2.5 percent HA demonstrated the maximum bending strength value and modulus among all the HA containing formulations. However there was no direct proportionality between the results of bending tests and the HA content and the addition of HA to PMMA (up to $10 \mathrm{wt} \%$ ) did not change the bending properties significantly.
\end{abstract}

Keywords: PMMA, Nano Hydroxyapatite, Mechanical Properties

\section{Introduction}

Polymethylmethacrylate (PMMA) is widely used as bone cement to secure orthopedic implants to the skeleton [1]. Because of its limited mechanical properties and poor compatibility with bone, the clinical use of this cement is accompanied by complications. Some examples of these limitations are brittleness and shrinkage of PMMA, void production in processing [2-4], lack of adherence to the bone $[5,6]$ and exothermic reaction of polymerization which can damage bone tissue $[7,8]$. To improve the noted deficiencies several investigators have studied bioceramic-reinforced polymer composite materials [9-12]. Hydroxyapatite (HA)-reinforced polymer composites are instances of these materials that can be used as bone cement, filling bone defects, coating of joint replacement prosthesis and dental implants [13]. Several investigators have studied HA-reinforced PMMA (PM-MA/HA) as a potential bone cement [10,14-16]. In fact addition of HA to the bone cement can improve biocompatibility and also enhance the mechanical properties of the cement because of its both biocompatibility and osteoconductivity [17-20]. Depending on HA amount added, mechanical and thermal properties of the cement can differ [21]. It is also reported that size and surface properties of the particles can increase or decrease the mechanical properties of the bone cement [12,22]. Vallo et al. [23] indicated that addition of up to $15 \mathrm{wt} \% \mathrm{HA}$ to a commercially available PMMA-based bone cement can improve the flexural modulus but with this amount of HA, the tensile and compressive strengths have been observed to remain constant in PMMA base cement. The fracture toughness of HA-reinforced PMMA has been observed to be increased by addition of $40 \mathrm{wt} \%$ HA [24]. Moursi et al. [25] have used three point bending test to investigate the effect of addition of HA on mechanical properties of PMMA cement. It is indicated that the presence of HA can increase the ultimate stress of PMMA from 4-44 MPa to $11-83 \mathrm{MPa}$. Kim et al. [11] produced a new bioactive bone cement that consists of HA, PMMA and chitosan. It was indicated that compressive strength of the cement was lower than the pure PMMA. Mechanical 
properties of acrylic base cements reinforced with HA have been studied by Serbetci et al. [12]. It was found that addition of HA caused to increase both compressive strength and fatigue life unlike tensile strength of the cement.

Wang et al. [26] and Roeder et al. [27] studied the effects of particle size and shape, and found that smaller particle size and larger aspect ratio increased the composite mechanical properties. Because there are few papers that study about addition of nano hydroxyapatite in PMMA, this study tries to fill this gap. In this research, mechanical properties of nano HA-reinforced PMMA cement were investigated by using three point bending, compressive and wear test.

\section{Experimental Procedure}

\subsection{Materials}

Cold-cure Acrylic powder (Acropars, Marlic) and Methyl Methacrylate (Acropars, Marlic) were used to produce Polymethylmethacrylate (PMMA) as the polymeric base of composite. Hydroxyapatite nano powders (catalogue No. 2196, Merck) were used as reinforcement phase (Figure 1).

\subsection{Sample Preparation}

For the preparation of samples, weighed amounts of PMMA and HA powders were mixed by a mixer mill (Retsich MM400, Germany) for 10 min with a vibration frequency of $20 \mathrm{~s}^{-1}$. The weight ratio of balls to powders was kept constant 8 (60 gram balls and 7.5 gram powders). After mixer milling, the same ratio of the solid/ liquid components were used in the preparation of compositions. The solid part was consisted of the mixed PMMA and HA powders and the liquid part was consisted of the PMMA monomer, the inhibitor and the catalyst. The weight ratio of the solid/liquid components was kept $5 / 3.5$ in all samples. For the cement dough preparation, the powder and the liquid parts were manually mixed together for $30 \mathrm{sec}$ at temperature of $25^{\circ} \mathrm{C} \pm 1{ }^{\circ} \mathrm{C}$ and the homogeneous dough obtained was kept for $2-4 \mathrm{~min}$ (depended on the sample) to reach the sticky state. In this step the dough was molded using compression molding method. After passing about $15 \mathrm{~min}$ the dough was hardened and the sample was ejected from the mold. The compositions of the samples are shown in Table $\mathbf{1}$.

To observe both size and shape of nano size hydroxyapatite powders, a transmission electron microscope, LEO 919 AB, was used. Figure 1 shows transmission electron microscope micrograph from nano size hydroxyapatite. These nano powders are flake in shape and their average size is about $50 \mathrm{~nm}$. The purity of hydroxyapatite nano powders that are used in this research was $99 \%$.

\subsection{Mechanical Evaluation}

Three kind of mechanical tests have been utilized to evaluate the properties of PMMA/nano-hydroxyapatite composites. Three-point bending, compression and wear tests were used. In three-point bending test, for each formulation 5 samples were tested with the strain rate of 5 $\mathrm{mm} / \mathrm{min}$. The dimensions of the samples were $3.3 \times 10 \times$ $64 \mathrm{~mm}$ and the. 5 samples were also used for each formulation in compressive strength test. The load rate was $2 \mathrm{~mm} / \mathrm{min}$ and the dimensions of the samples were $4 \times 4$ $\times 8 \mathrm{~mm}$. In both tests universal tensile machine Zwick model was utilized. For each run, 3 samples were tested and the average values were tabulated.

In this research, the wear test method of pin on disc was utilized. 5 samples were tested for each formulation (according to Table 1). Each sample prepared with base area of $4 \mathrm{~mm}^{2}$ and $10 \mathrm{~mm}$ height which was attached to a

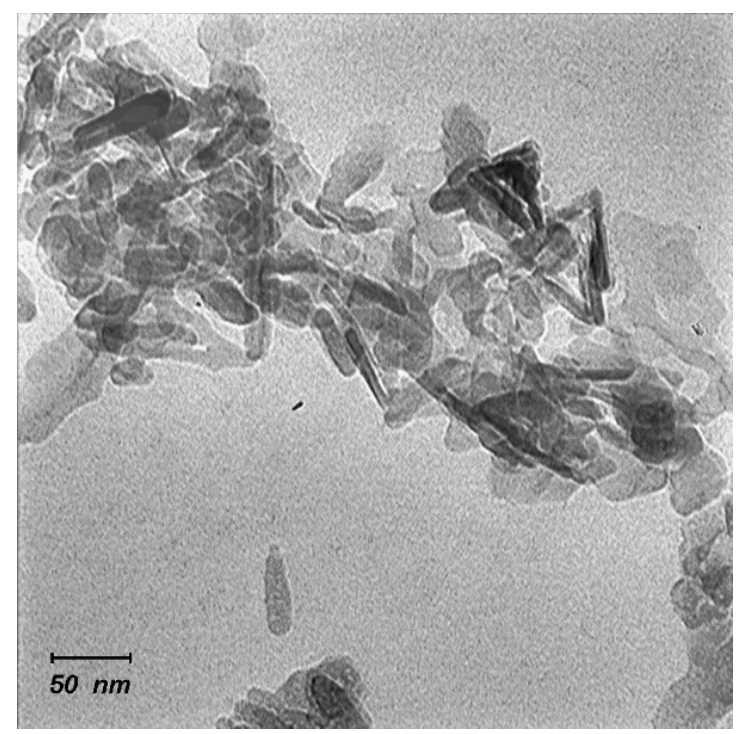

Figure 1. TEM micrograph of nano sized hydroxyapatite.

Table 1. The details of the composition of each composite sample.

\begin{tabular}{ccc}
\hline Notation of samples & $\begin{array}{c}\text { HA } \\
(\mathbf{w t} \%)\end{array}$ & $\begin{array}{c}\text { Mixer milling time } \\
\text { (min) }\end{array}$ \\
\hline PMMA neat & 0 & 0 \\
PMMA & 0 & 10 \\
PMMA/2.5HA & 2.5 & 10 \\
PMMA/5HA & 5 & 10 \\
PMMA/10HA & 10 & 10 \\
\hline
\end{tabular}


removable sample holder with cyanoacrylate glue. In the current study a special wear device was developed. The device was consisted of an aluminum holder that can freely move up and down to allow specimens to be under a certain force at all times during the tests. The device rotated one orbit per second and number of turns recorded digitally for each run. A brass cup with interior diameter of $26 \mathrm{~mm}$ was utilized as container of artificial saliva and as holder of abrasive plate $\left(\mathrm{Al}_{2} \mathrm{O}_{3}\right.$ abrasive plate with diameter of $25 \mathrm{~mm}$, Dedeco, \#309-0009). The device is shown in Figure 2. Each specimen was abraded by 5000 and 10,000 orbits. Samples were weighted with the accuracy of $\pm 0.00001 \mathrm{~g}$ before and after testing. Two conditions were used for this test: 5 cc Fusayama Meyer artificial saliva [28] and atmosphere. After each 5000 and 10,000 orbits, both saliva and abrasive plates were replaced, samples weights were measured and wear rate was calculated by the following formula

$$
\text { Wear Rate }=\frac{\Delta W}{L}
$$

where $\Delta W$ is the difference of weight measurement before and after each 5000 and 10,000 orbits and $L$ (in meter) is the distance for each 5000 and 10,000 rotations can be calculated as follows,

$$
\begin{aligned}
& L_{2000}=5000 \times 2 \pi R=785.4 \mathrm{~m} \\
& L_{7000}=10000 \times 2 \pi R=1570.8 \mathrm{~m}
\end{aligned}
$$

Chewing stress on occlusal surface of teeth is varying between $0.8-1.75 \mathrm{MPa}$ [29]. Thus in this research we used the force of $4 \mathrm{~N}$ to obtain $1 \mathrm{MPa}$ stress on specimens.

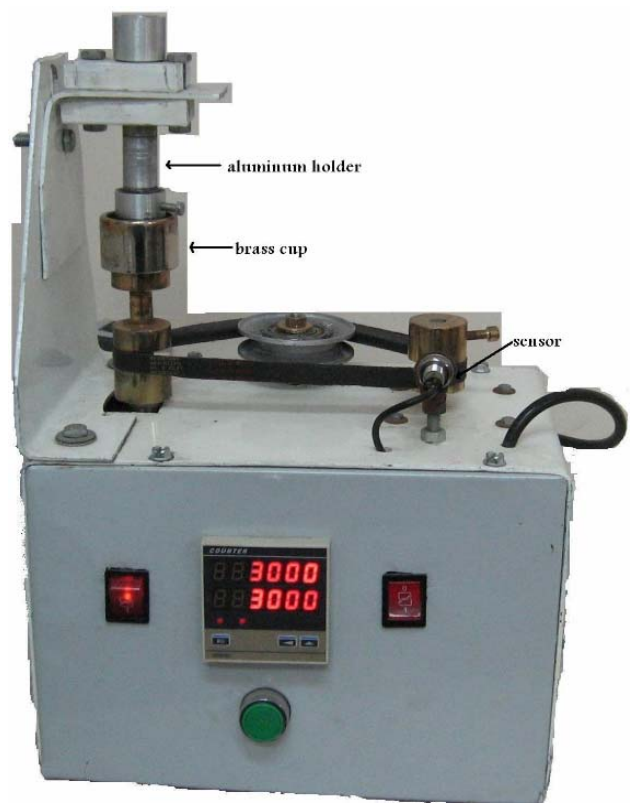

Figure 2. Wear device which was used in this investigation.

\section{Results and Discussions}

\subsection{Compression Test}

Surgical PMMA cement is brittle in nature. Like all other brittle materials, it is weak under tension but quite strong in compression, and is capable of yielding under uniaxial compression. The main direction of load on bone cement in a total hip implant is compression, and therefore the measurements of compression yield strength values of the prepared cements are very important [30].

The average values of ultimate compressive strength $\left(\sigma_{C}\right)$, elongation at break $\left(\varepsilon_{f C}\right)$, compressive elastic modulus $\left(E_{C}\right)$ and compression yield strength $\left(\sigma_{y}\right)$ of the cement samples are given in Table 2. The schematic figure of these values is shown in Figure 3.

According to the results, PMMA cements containing 2.5 percent HA had the maximum value of ultimate compressive strength, elastic modulus of compression and compression yield strength among all other formulations. Also the minimum value of elongation at break was also in this sample. It was observed that HA addition more than $2.5 \mathrm{wt} \%$ caused a decrease of ultimate compressive strength and compression yield strength. In elongation at break results, it was observed that HA addition more than $2.5 \mathrm{wt} \%$ caused an increase in these values. Although the results of elongation at break were

Table 2. The results of the compression test of each composite sample.

\begin{tabular}{ccccc}
\hline Sample & $\boldsymbol{\sigma}_{\boldsymbol{C}}$ & $\boldsymbol{\varepsilon}_{f C}$ & $\boldsymbol{E}_{\boldsymbol{C}}$ & $\boldsymbol{\sigma}_{\boldsymbol{y}}$ \\
\hline PMMA neat & 222 & 4.0 & 29 & 131 \\
PMMA & 188 & 4.1 & 26 & 98 \\
PMMA/2.5HA & 254 & 3.7 & 36 & 124 \\
PMMA/5HA & 203 & 4.1 & 24 & 83 \\
PMMA/10HA & 186 & 4.2 & 26 & 83 \\
\hline
\end{tabular}

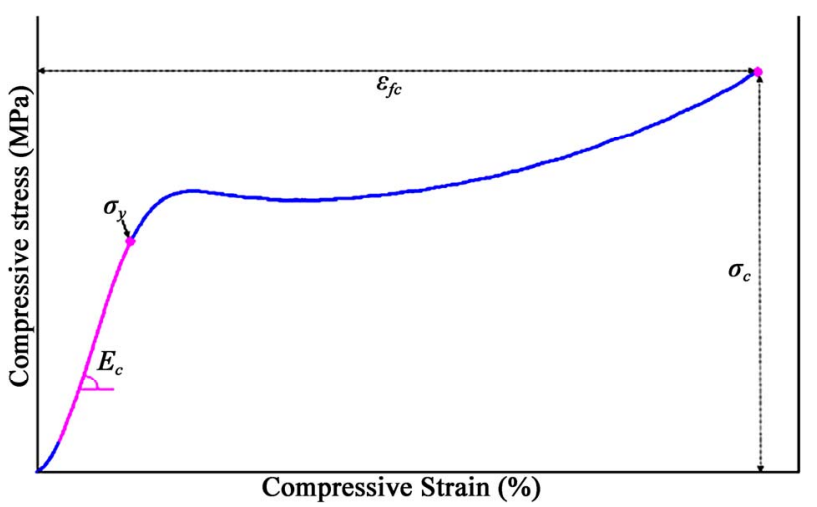

Figure 3. The values of ultimate compressive strength $\left(\sigma_{C}\right)$, elongation at break $\left(\varepsilon_{f C}\right)$, compressive elastic modulus $\left(E_{C}\right)$ and compression yield strength $\left(\sigma_{y}\right)$ of the cement samples. 
very close to each other, and there was no direct proportionality between the results of elastic modulus of compression and the HA content.

In most, but not all, composites, ultimate compressive strength decreases with increasing filler content and average particle size. The decrease in ultimate compressive strength and compression yield strength can be explained as follows. During the setting and cooling stage of PMMA, since the shrinkage of PMMA matrix is more than the shrinkage of HA particles, HA particles would be firmly entrapped and squeezed in the PMMA matrix. As a result of this, a circumferential tensile stress forms in the bone cement matrix that is adjacent to HA particles. This stress is a hoop stress and it simulates the case of weak bonding between HA particles and PMMA matrix (Figure 4) [30]. In the case of load application, the HA particles in the continuous phase of PMMA constitute a second phase, and the interface between the two phases acts like a grain boundary resisting propagation of a crack. A friction force that is opposite to the direction of the crack initiating force will be present at the edges of the crack. The hoop stress is still present at that site, but the magnitude of the friction force is probably higher than the circumferential force. The hoop stress helps the crack edges to be separated (Figure 5) [30]. The weak bonding area produced between these two phases may cause a decrease in ultimate compressive strength and compression yield strength.
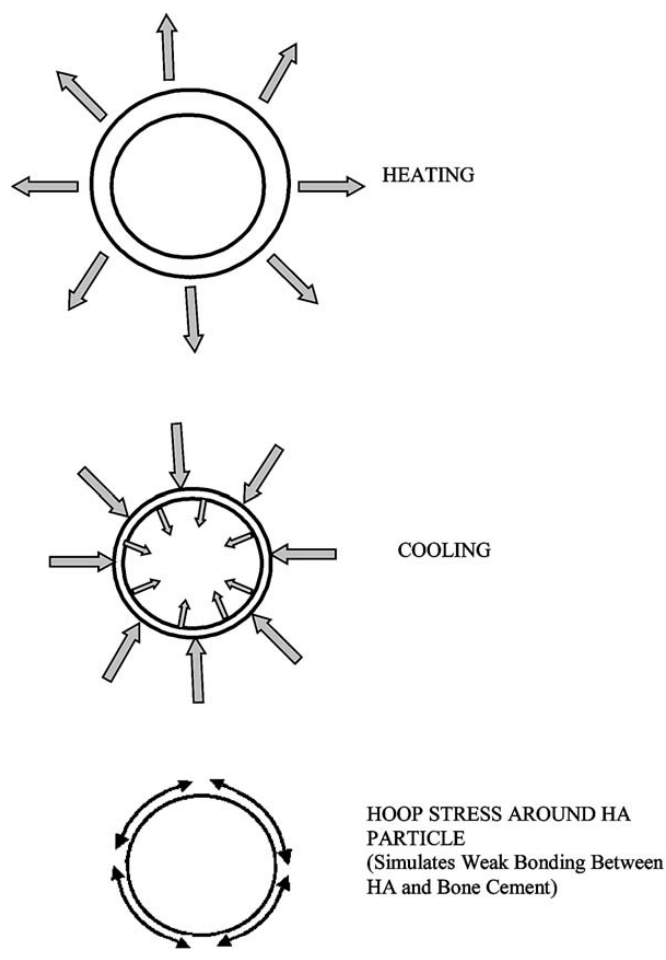

Figure 4. Mechanism of the formation of mechanical bonding between bone cement matrix and HA particle [30].

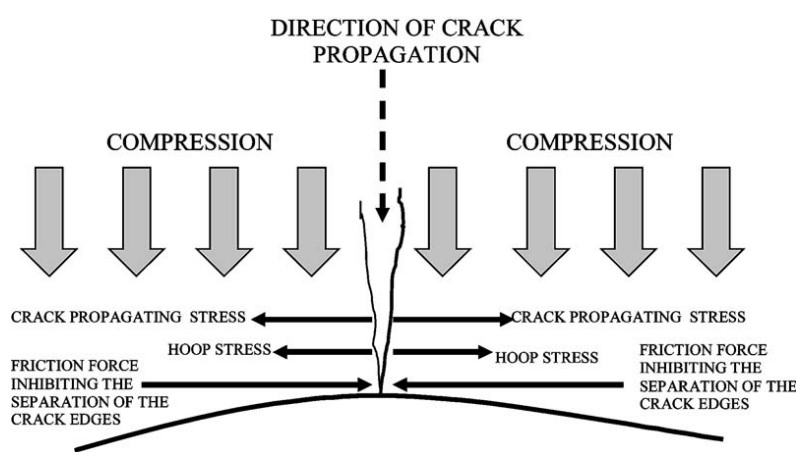

Figure 5. Effect of loading direction on crack propagation in compressive loading [30].

In addition, this is in accordance with the reports that addition of HA without any chemical treatment decreased the mechanical strength of the bone cement. The observed compressive behavior can be explained by the degree of adhesion between the HA articles and the matrix. Poor adhesion between the components causes a decrease in yield stress as if the system is filled with voids. HA nanoparticles behave as load carriers leading to good mechanical properties if they are present in small amounts and distributed homogeneously in the cement dough (like PMMA-2.5HA sample). If the proportion of the HA particles increases, this could lead to non-homogeneous distribution and, therefore, aggregation of particles may occur. This may cause phase segregation and non-homogeneity in the structure and poor adhesion to the matrix leading to a decrease in the compressive strength [30].

Except elastic modulus of compression that it's values were very close to each other, all the other values $\left(\sigma_{C}, \varepsilon_{f C}\right.$ and $\sigma_{y}$ ) decreased by applying the mixer milling process (PMMA-neat and PMMA samples). It can be inferred that the changes take place in polymer structure through milling cause the changes of compression parameters significantly.

\subsection{Three-Point Bending Test}

The average values of ultimate bending strength $\left(\sigma_{b}\right)$, elongation at break $\left(\varepsilon_{f b}\right)$ and elastic modulus of bending $\left(E_{b}\right)$ are given in Table 3 . The schematic figure of these values is shown in Figure 6.

Table 3. The results of the three-point bending test of each composite sample.

\begin{tabular}{cccc}
\hline Sample & $\sigma_{b}$ & $\varepsilon_{f b}$ & $E_{b}$ \\
\hline PMMA neat & 59 & 3.0 & 1.9 \\
PMMA & 65 & 3.5 & 1.8 \\
PMMA/2.5HA & 67 & 3.5 & 2.0 \\
PMMA/5HA & 64 & 3.6 & 1.8 \\
PMMA/10HA & 67 & 3.7 & 1.9 \\
\hline
\end{tabular}




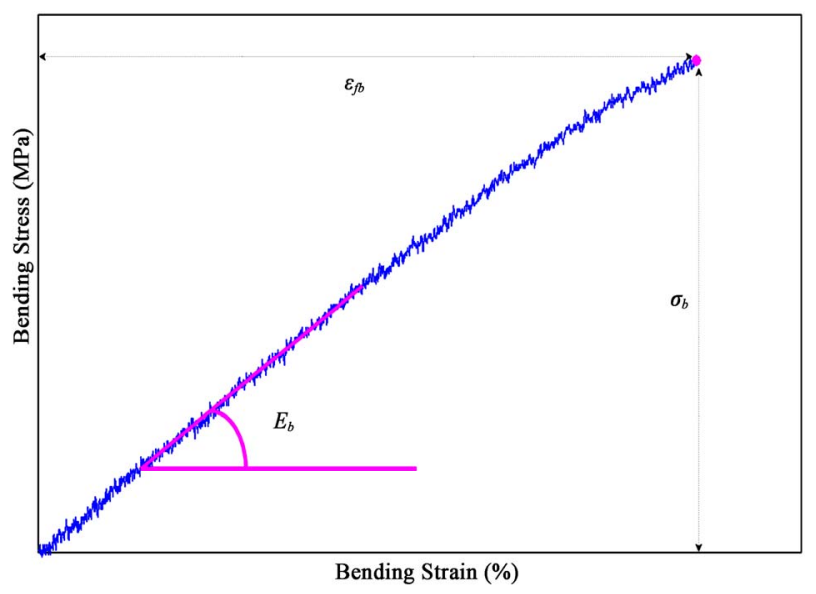

Figure 6. The values of ultimate bending strength $\left(\sigma_{b}\right)$, elongation at break $\left(\varepsilon_{f b}\right)$ and elastic modulus of bending $\left(E_{b}\right)$ of the cement samples.

PMMA cements containing 2.5 and 10 percents HA demonstrated the maximum bending strength value (67 $\mathrm{MPa}$ ) among all the HA containing formulations. However there was no direct proportionality between the results of bending strength and the HA content. Furthermore increasing the HA content caused the slight increased of elongation at break. Also the result showed that elastic modulus of bending in PMMA cements containing 2.5 percent HA had the maximum value between the samples. But, there was no direct proportionality between the results of these values and the HA content totally. However the results of ultimate bending strength, elongation at break and elastic modulus of bending were very close to each other. So it can be inferred that the addition of HA to PMMA (up to $10 \mathrm{wt} \%$ ) did not change the bending properties significantly. But, it can be said that the mixer milling process had the significant effect on increasing of bending strength and elongation at break in PMMA samples (PMMA-neat and PMMA samples). So similar to compression results tests the milling process causes the changes of bending parameters significantly.

\subsection{Wear Test}

Figure 7 shows the results of wear tests in atmosphere. It can be observed that wear rate decreases by increasing in HA content. This is because of presence of ceramic powders of HA which have high hardness that can improve sliding wear rate [31]. For PMMA/2.5\%HA comparing to pure PMMA, this improvement in wear rates is more obvious which emphasis the role of HA in improvement of wear rate. For both 5000 and 10,000 orbit this trend can be observed.

Figure 8 shows the results of wear test in Fusayama
Meyer artificial saliva. As seen, because of third body abrasion effect, the improvement in wear rate of PMMA at the presence of HA nano powders is greater than atmosphere. Abraded particles act as an additional abrasive surface and cause more wear [31-34]. During "mastication" in the mouth, this type of wear occurs and is prevalent in patients who eat abrasive diet such as grained bread. In wet condition (saliva) the abraded particles are removed from the surface but it can not happen in dry condition (atmosphere). This is the reason for higher wear rate in atmosphere in comparison with saliva. Both Figures 7 and 8 shows that there is no significant difference between wear rate of neat and mixer milled PMMA.

Figures 9 and $\mathbf{1 0}$ are comparisons between 5000 and 10,000 rotations in saliva and atmospheric media. In both figures it can be observed that there is a higher wear rate in atmospheric media in comparison with saliva. As it was mentioned, this is because of more third body abrasion in atmosphere than in saliva.

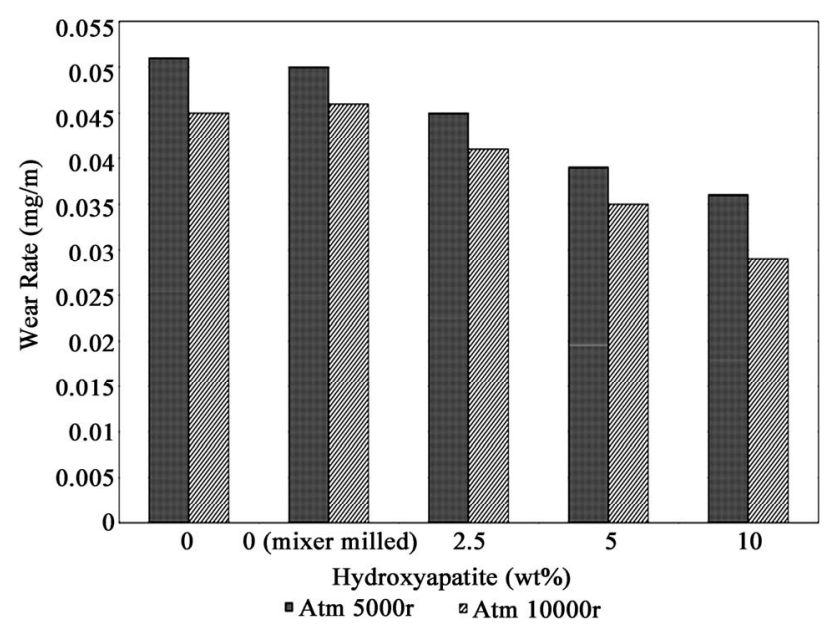

Figure 7. Wear test in atmosphere.

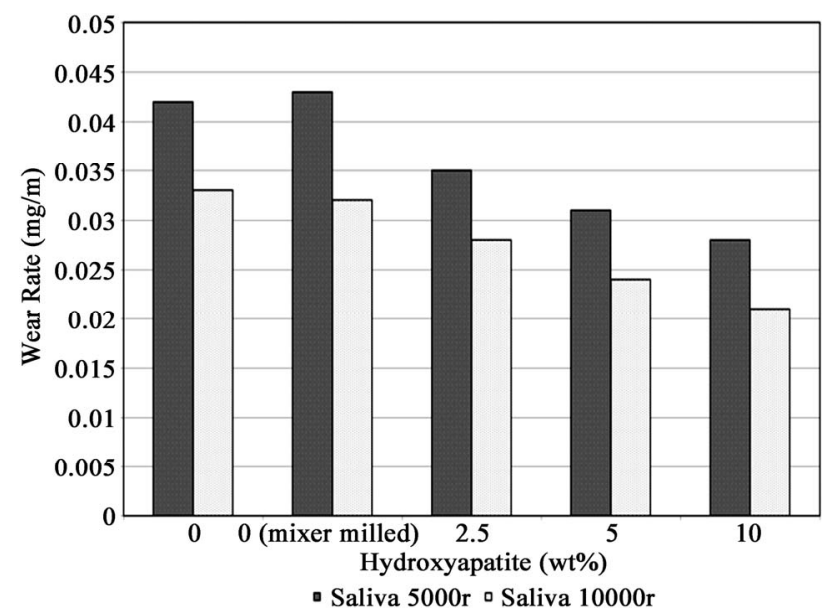

Figure 8. Wear test in Fusayama Meyer artificial saliva. 


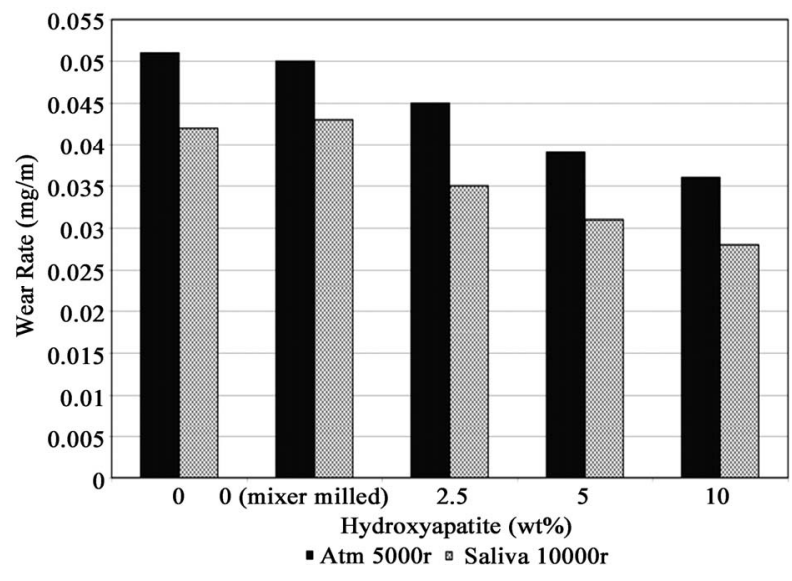

Figure 9. Comparison between Wear tests in Fusayama Meyer artificial saliva and atmosphere in 5000 orbits.

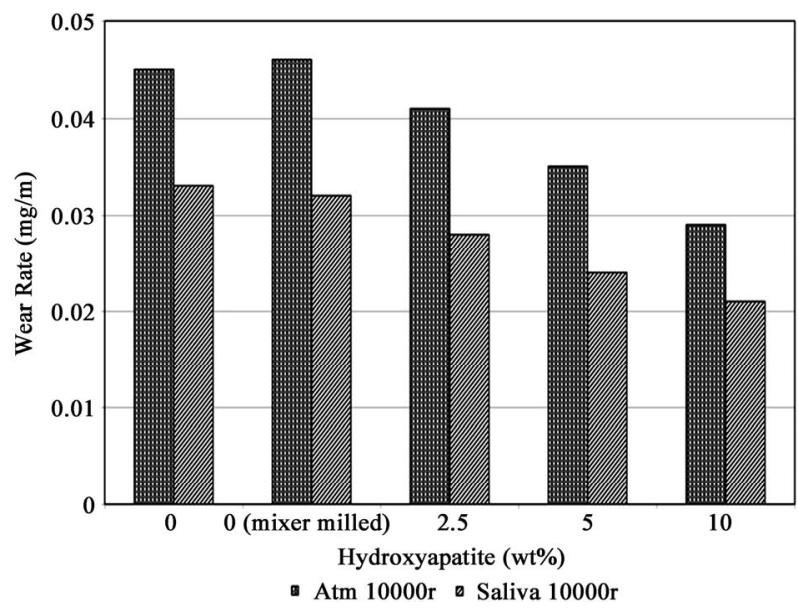

Figure 10. Comparison between Wear tests in Fusayama Meyer artificial saliva and atmosphere in 10,000 orbits.

\section{Conclusions}

To investigate the role of HA on mechanical properties of PMMA, Wear test, compression and three-point bending tests was carried out. The results of current study might be summarized as follows:

1) Wear rate decreases by increasing in HA content in both atmosphere and artificial saliva.

2) There was no direct proportionality between the results of compression tests and the HA content.

3) The addition of HA to PMMA (up to $10 \mathrm{wt} \%$ ) did not change the bending properties significantly.

4) The mixer milling process causes the significant changes of mechanical properties of PMMA.

\section{Acknowledgements}

The authors are grateful to the deputy of research of Ferdowsi University of Mashhad for financial support.

\section{References}

[1] S. Santavirta, M. Takagi, E. Gomez-Barren, J. Nevalainen, J. Lassus, J. Salo and Y. T. Konttinen, "Studies of Host Response to Orthopedic Implants and Biomaterials," Journal of Long-Term Effects of Medical Implants, Vol. 9, 1999, pp. 67-76.

[2] G. Lewis, "Properties of Acrylic Bone Cement: State of the Art Review," Journal of Biomedical Materials Research, Vol. 38, No. 2, 1997, pp. 155-182. doi:10.1002/(SICI)1097-4636(199722)38:2<155::AID-JB M10>3.0.CO;2-C

[3] E. J. Harper and W. Bonfield, "Tensile Characteristics of Ten Commercial, Acrylic Bone Cements," Journal of Biomedical Materials Research, Vol. 53, No. 5, 2000, pp. 605-616.

doi:10.1002/1097-4636(200009)53:5<605::AID-JBM22> 3.0.CO;2-5

[4] J. E. Barralet, T. Gaunt, A. J. Wright, I. R. Gibson and J. C. Knowles, "Effect of Porosity by Compaction on Compressive Strength and Microstructure of Calcium Phosphate Cement," Journal of Biomedical Materials Research Part B, Applied Biomaterials, Vol. 63, No. 1, 2002, pp. 1-9. doi:10.1002/jbm.1074

[5] G. Zambonin, S. Colucci, F. Cantatore and M. Grano, "Response of Human Osteoblasts to Polymethylmetacrylate in Vitro," Calcified Tissue International, Vol. 62, No. 4, 1998, pp. 362-365. doi:10.1007/s002239900445

[6] G. Cunin, H. Boissonnet, H. Petite, C. Blanchat and G. Guillemin, "Experimental Vertebroplasty Using Osteoconductive Granular Material," Spine, Vol. 25, No. 9, 2000, pp. 1070-1076. doi:10.1097/00007632-200005010-00006

[7] J. X. Lu, Z. W. Huang and P. Tropiano, "Human Biological Reactions at the Interface between Bone Tissue and Polymethylmethacrylate Cement," Journal of Materials Science: Materials in Medicine, Vol. 13, No. 8, 2002, pp. 803-809. doi:10.1023/A:1016135410934

[8] P. F. Heini, B. Walchli and U. Berlemann, "Percutaneous Transpedicular Vertebroplasty with PMMA: Operative Technique and Early Results," European Spine Journal, Vol. 9, No. 5, 2000, pp. 445-450. doi: $10.1007 / \mathrm{s} 005860000182$

[9] S. Shinzato, T. Nakamura, T. Kokubo and Y. Kitamura, "Bioactive Bone Cement: Effect of Silane Treatment on Mechanical Properties and Osteoconductivity," Journal of Biomedical Materials Research, Vol. 55, No. 3, 2001, pp. $277-284$

doi:10.1002/1097-4636(20010605)55:3<277::AID-JBM1 015>3.0.CO;2-5

[10] W. R. Walsh, M. J. Svehla, J. Russell, M. Saito, T. Nakashimac, R. M. Gilliesa, W. Brucea and R. Hori, "Cemented Fixation with PMMA or Bis-GMA Resin Hydroxyapatite Cement: Effect of Implant Surface Roughness," Biomaterials, Vol. 25, No. 20, 2004, pp. 49294934. doi:10.1016/i.biomaterials.2003.12.020

[11] K. S. Bong, K. Y. Jick, Y. T. Lim nd A. P. Su, "The Characteristics of a Hydroxyapatite-Chitosan-PMMA Bone Cement," Biomaterials, Vol. 25, No. 26, 2004, pp. 5715-5723. 
[12] K. Serbetci, F. Korkusuz and N. Hasirci, "Thermal and Mechanical Properties of Hydroxyapatite Impregnated Acrylic Bone Cements," Polymer Testing, Vol. 23, No. 2, 2004, pp. 145-155. doi:10.1016/S0142-9418(03)00073-4

[13] S. Morita, K. Furuya, K. Ishihara and N. Nakabayashi, "Performance of Adhesive Bone Cement Containing Hydroxyapatite Particles," Biomaterials, Vol. 19, No. 17, 1998, pp. 1601-1606. doi:10.1016/S0142-9612(97)00120-8

[14] T. W. Bauer and J. Schils, "The Pathology of Total Joint Arthroplasty.I. Mechanisms of Implant Fixation," Skeletal Radiology, Vol. 28, No. 8, 1999, pp. 423-432. doi:10.1007/s002560050541

[15] S. Shinzato, M. Kobayashi, W. F. Mousa, M. Kamimura, M. Neo, Y. Kitamura, T. Kokubo and T. Nakamura, "Bioactive Polymethyl Methacrylate-Based Bone Cement: Comparison of Glass Beads, Apatite- and Wollastonite-Containing Glassceramic, and Hydroxyapatite Fillers on Mechanical and Biological Properties," Journal of Biomedical Materials Research, Vol. 51, No. 2, 2000, pp. 258-272. doi:10.1002/(SICI)1097-4636(200008)51:2<258::AID-JB M15>3.0.CO;2-S

[16] H. Itokawaa, T. Hiraideb, M. Moriyaa, M. Fujimotoa, G. Nagashimaa, R. Suzukia and T. Fujimoto, "A 12 Month in Vivo Study on the Response of Bone to a Hydroxyapatite Polymethylmethacrylate Cranioplasty Composite," Biomaterials, Vol. 28, No. 3, 2007, pp. 4922-4927. doi:10.1016/j.biomaterials.2007.08.001

[17] M. J. Dalby, L. Di Silvio, E. J. Harper and W. Bonfield, "Initial Interaction of Osteoblasts with the Surface of Hydroxyapatite-Poly(Methylmethacrylate) Cement," Biomaterials, Vol. 22, No. 13, 2001, pp. 1739-1747. doi:10.1016/S0142-9612(00)00334-3

[18] M. J. Dalby, S. L. Di, E. J. Harper and W. Bonfield, "Increasing Hydroxyapatite Incorporation into Poly (Methylmethacrylate) Cement Increases Osteoblast Adhesion and Response," Biomaterials, Vol. 23, No. 2, 2002, pp. 569-576. doi:10.1016/S0142-9612(01)00139-9

[19] T. Saito, Y. Kin and T. Koshino, "Osteogenic Response of Hydroxyapatite Cement Implanted into the Femur of Rats with Experimentally Induced Osteoporosis," Biomaterials, Vol. 23, No. 13, 2002, pp. 2711-2716. doi:10.1016/S0142-9612(02)00003-0

[20] R. D. Welch, B. H. Berry, K. Crawford, H. Zhang, M. Zobitz, D. Bronson and S. Krishnan, "Subchondral Defects in Caprine Femora Augmented with in Situ Setting Hydroxyapatite Cement, Polymethylmethacrylate, or Autogenous Bone Graft: Biomechanical and Histomorphological Analysis after Two-Years," Journal of Orthopaedic Research, Vol. 20, No. 3, 2002, pp. 464-472. doi:10.1016/S0736-0266(01)00124-3

[21] K. S. Erbetc, F. Korkusuz and N. Hasırc1, "Mechanical and Thermal Properties of Hydroxyapatite-Impregnated Bone Cement," Turkish Journal of Medical Sciences, Vol. 30, No. 6, 2000, pp. 543-549.

[22] S. Y. Kwon, Y. S. Kim, Y. K. Woo, S. S. Kim and J. B. Park, "Hydroxyapatite Impregnated Bone Cement: In Vi- tro and in Vivo Studies," Bio-Medical Materials and Engineering, Vol. 7, No. 2, 1997, pp. 129-140.

[23] C. I. Vallo, P. E. Montemartini and M. A. Fanovich, "Polymethylmethacrylate-Based Bone Cement Modified with Hydroxyapatite," Journal of Biomedical Materials Research Part B, Applied Biomaterials, Vol. 48, No. 2, 1999, pp. 150-158. doi:10.1002/(SICI)1097-4636(1999)48:2<150::AID-JBM 9>3.0.CO;2-D

[24] K. Ishihara, H. Arai and N. Nakabayashi, "Adhesive Bone Cement Containing Hydroxyapatite Particle as Bone Compatible Filler," Journal of Biomedical Materials Research, Vol. 26, No. 8, 1992, pp. 937-945. doi:10.1002/jbm.820260708

[25] M. M. Amr, A. V. Winnarda, P. L. Winnarda, J. J. Lannuttib and R. R. Seghi, "Enhanced Osteoblast Response to a Polymethylmethacrylate-Hydrox-Yapatite Composite," Biomaterials, Vol. 23, No. 1, 2002, pp. 133-144. doi:10.1016/S0142-9612(01)00088-6

[26] M. Wang, R. Joseph and W. Bonfield, "Hydroxyapatitepolyethylene Composites for Bone Substitution: Effects of Ceramic Particle Size and Morphology," Biomaterials, Vol. 19, No. 24, 1998, pp. 2357-2366. doi:10.1016/S0142-9612(98)00154-9

[27] R. K. Roeder, M. M. Sproul and C. H. Turner, "Hydroxyapatite Whiskers Provide Improved Mechanical Properties in Reinforced Polymer Composites," Journal of Biomedical Materials Research Part A, Vol. 67A, No. 3, 2003, pp. 801-812. doi:10.1002/jbm.a.10140

[28] J. M. Meyer and J. N. Nally, "Influence of Artificial Salivas on the Corrosion of Dental Alloys," Journal of Dental Research, Vol. 54, 1975, pp. 678-681.

[29] X. Q. Hu, P. M. Marquis and A. C. Shortall, "Two Body in Vitro Wear Study of Some Current Dental Composites and Amalgam," Journal of Prosthetic Dentistry, Vol. 82, No. 2, 1999, pp. 214-220. doi:10.1016/S0022-3913(99)70159-9

[30] K. Serbetci, F. Korkusuz and N. Hasirci, "Thermal and Mechanical Properties of Hydroxyapatite Impregnated Acrylic Bone Cements," Polymer Testing, Vol. 23, No. 2, 2004, pp. 145-155. doi:10.1016/S0142-9418(03)00073-4

[31] A. Dasari, Z. Z. Yu and Y. W. Mai, "Fundamental Aspect and Recent Progress on Wear/Scratch Damage in Polymer Nanocomposites," Materials Science and Engineering: Reports, Vol. 63, No. 2, 2009, pp. 31-80. doi:10.1016/j.mser.2008.10.001

[32] A. Dasari, "On Toughening and Wear/Scratch Damage in Polymer Nanocomposites," PhD Thesis, the University of Sydney, Sydney, 2007.

[33] Q. B. Guo, M. Z. Rong, G. L. Jia, K. T. Lau and M. Q. Zhang, "Sliding Wear Performance of Nano-SiO ${ }_{2} /$ Short Carbon Fiber/Epoxy Hybrid Composites," Wear, Vol. 266, No. 7-8, 2009, pp. 658-665. doi:10.1016/j.wear.2008.08.005

[34] L. H. Mair, "Wear in the Mouth: The Tribological Dimension," M. Addy, Martin Dunitz Ltd., London, 2000, pp. 181-188. 